\title{
Electron Microscopy Studies of V-P-O Catalyst Precursors: Defining the Dihydrate to Hemihydrate Phase Transformation
}

\author{
W. Weng*, R. Al Otaibi**, N.F. Dummer**, J.K. Bartley**, G.J. Hutchings** and C.J. Kiely* \\ * Department of Materials Science \& Engineering, Lehigh University, Bethlehem, PA 18015, USA \\ ** Cardiff Catalysis Institute, School of Chemistry, Cardiff University, Cardiff, CF10 3AT, UK
}

Vanadium phosphate (V-P-O) catalysts are used commercially for the selective oxidation of $n$ butane to maleic anhydride, and represent one of the most well studied heterogeneous mixed oxide catalysts [1]. The catalytically active pyrophosphate phase, $\left((\mathrm{VO})_{2} \mathrm{P}_{2} \mathrm{O}_{7}\right)$, is obtained by activating a hemihydrate precursor $\left(\mathrm{VOHPO}_{4} \cdot 0.5 \mathrm{H}_{2} \mathrm{O}\right)$ under reaction conditions. The details of the hemihydrateto-pyrophosphate structural transformation that occurs during this activation process have been solved previously by electron microscopy [2]. A common method, denoted the "VPD" route, for preparing the $\mathrm{VOHPO}_{4} \cdot 0.5 \mathrm{H}_{2} \mathrm{O}$ precursor involves reacting $\mathrm{V}_{2} \mathrm{O}_{5}$ with $\mathrm{H}_{3} \mathrm{PO}_{4}$ to form the layered $\left(\mathrm{V}^{5+}\right)$ dihydrate phase $\left(\mathrm{VOPO}_{4} \cdot 2 \mathrm{H}_{2} \mathrm{O}\right)$, which is then subsequently reduced using an alcohol to form the hemihydrate precursor (a $\mathrm{V}^{4+}$ phase). The structural details of this dihydrate-to-hemihydrate structural transformation are poorly documented and form the basis of this study.

In this study, starting from a standard $\mathrm{VOPO}_{4} \cdot 2 \mathrm{H}_{2} \mathrm{O}$ material, either 1-butanol or an $n$-octane/1butanol combination were used in the reduction stage to produce the hemihydrate precursor, as summarized in Reaction Scheme 1. Scanning electron microscopy (SEM), transmission electron microscopy (TEM) and selected area electron diffraction (SAED) analyses indicate that 1-butanol directly reduces and delaminates the cuboidal $\mathrm{VOPO}_{4} \cdot 2 \mathrm{H}_{2} \mathrm{O}$ crystallites (Fig. 1a) into $\mathrm{VOHPO}_{4} \cdot 0.5 \mathrm{H}_{2} \mathrm{O}$ with a characteristic rosette morphology (denoted as VPDB, Fig. 1b). In contrast, $n$-octane had the effect of changing the $\mathrm{VOPO}_{4} \cdot 2 \mathrm{H}_{2} \mathrm{O}$ blocks into octagonal $\mathrm{VOPO}_{4} \cdot 2 \mathrm{H}_{2} \mathrm{O}$ crystallites (denoted as VPDO, Fig. 1c), which could then be subsequently reduced with 1-butanol to form $500 \mathrm{~nm}$ long, $40 \mathrm{~nm}$ thick rhomboidal platelets of $\mathrm{VOHPO}_{4} \cdot 0.5 \mathrm{H}_{2} \mathrm{O}$ (denoted as VPDOB, Fig. 1d). The dihydrate precursors were further studied by comparing the effects of exposure of the VPD and VPDO materials to 1-butanol for 1 minute at room temperature. SEM analyses (Fig. 2) show that both platelets exhibit signs of slight delamination at the edges after interaction with 1-butanol. Many square etch pits on the [001] surface with (100) and (010) facet edges are present in the VPD dihydrate, whereas equivalent etch pits were rarely found in the corresponding VPDO sample.

A possible mechanism for the transformation of $\mathrm{VOPO}_{4} \cdot 2 \mathrm{H}_{2} \mathrm{O}$ to $\mathrm{VOHPO}_{4} \cdot 0.5 \mathrm{H}_{2} \mathrm{O}$ has been determined from detailed TEM, SAED and XRD observations on this set of materials. Both the $\mathrm{VOPO}_{4} \cdot 2 \mathrm{H}_{2} \mathrm{O}$ and $\mathrm{VOHPO}_{4} \cdot 0.5 \mathrm{H}_{2} \mathrm{O}$ platelets exhibit a layered morphology having basal planes with [001] platelet normals (i.e. [001] $]^{\text {dihyd }}$ remains oriented parallel to [001] $]^{\text {hemi }}$ during the transformation). The presence or absence of exposed $(100)^{\text {dihyd }}$ and $(010)^{\text {dihyd }}$ facet planes during the alcohol reduction/dehydration of the $\mathrm{VOPO}_{4} \cdot 2 \mathrm{H}_{2} \mathrm{O}$ material are very important in determining the morphology of the resulting hemihydrate precursor (Figure 1). When these specific planes are exposed, they can be easily attacked by 1-butanol, resulting in a rosette type $\mathrm{VOHPO}_{4} \cdot 0.5 \mathrm{H}_{2} \mathrm{O}$ morphology with (220) planes dominating the XRD patterns. Hence it is reasonable to assume that the initial $[100]^{\text {dihyd }}$ direction is parallel to the final $[110]^{\text {hemi }}$ direction. In other words the orientation relationship between $\mathrm{VOPO}_{4} \cdot 2 \mathrm{H}_{2} \mathrm{O}$ and $\mathrm{VOHPO}_{4} \cdot 0.5 \mathrm{H}_{2} \mathrm{O}$ is: $[001]^{\text {dihyd }} / /[001]^{\text {hemi }}$ and [100] dihyd $/ /$ 
$[110]^{\text {hemi }}$ as shown schematically in Fig. 3. The transformation from $\mathrm{VOPO}_{4} \cdot 2 \mathrm{H}_{2} \mathrm{O}$ to $\mathrm{VOHPO}_{4} \cdot 0.5 \mathrm{H}_{2} \mathrm{O}$ can be envisaged to occur in the following sequence of steps. Firstly pairs of adjacent $\mathrm{VO}_{6}$ octahedra shuffle towards one another in a co-ordinated fashion along the [110] ${ }^{\text {dihyd }}$ direction (as indicated by the arrows in Fig. 3a) and connect together such that they share a common edge. To facilitate this, two oxygen atoms are lost from one octahedral unit in the pair. This can also be viewed as one $\mathrm{P}-\mathrm{O}-\mathrm{V}$ bond being broken for every tetrahedral $\mathrm{PO}_{4}$ group, leaving an unshared corner oxygen in the $\mathrm{PO}_{4}$ tetrahedral unit. Meanwhile one water molecule that is hydrogen bonded to each $\mathrm{PO}_{4}$ group escapes from the structure giving rise to a transient $\mathrm{VOPO}_{4} \cdot \mathrm{H}_{2} \mathrm{O}$ monohydrate phase. Next the connected pairs of $\mathrm{VO}_{6}$ octahedral units in the monohydrate orient to become face-sharing and yet another oxygen atom is lost from each octahedral pair (which then becomes incorporated in another escaping water molecule). Simultaneously the $\mathrm{V}^{5+}$ cations within each of the $\mathrm{VO}_{6}$ octahedral units reduce to $\mathrm{V}^{4+}$ to ensure charge neutrality. The final result is that the $\mathrm{VOHPO}_{4} \cdot 0.5 \mathrm{H}_{2} \mathrm{O}$ structure is topotactically generated which preferentially exposes the $(001)^{\text {hemi }}$ basal plane.

\section{References}

[1] E. Bordes, Catal. Today 1 (1987) 499.

[2] C.J. Kiely et al., Faraday Discussions 105 (1996) 103.

[3] The authors acknowledge financial support from the NSF - Materials World Network Program (Grant \# DMR-0709887).

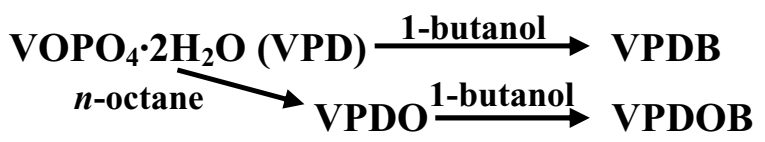

Scheme 1. The reduction routes of $\mathrm{VOPO}_{4} \cdot 2 \mathrm{H}_{2} \mathrm{O}$ explored in this work.

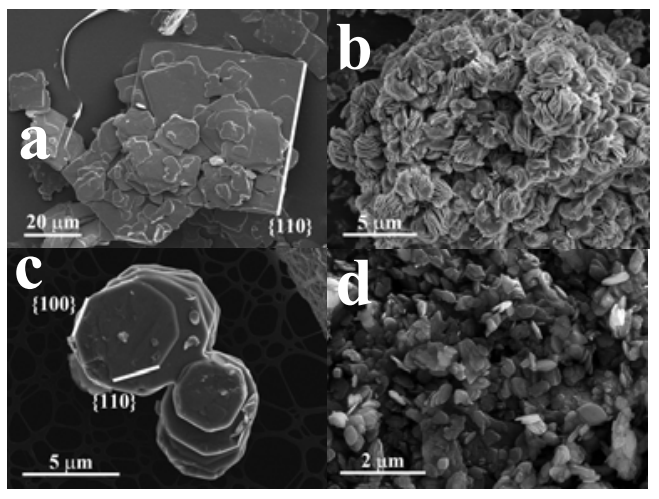

Figure 1. SEM micrographs of (a) the starting $\mathrm{VOPO}_{4} \cdot 2 \mathrm{H}_{2} \mathrm{O}$ material (VPD) showing a cuboidal morphology with $\{110\}$-type termination facets; (b) catalyst precursor $\mathrm{VOHPO}_{4} \cdot 0.5 \mathrm{H}_{2} \mathrm{O}(\mathrm{VPDB})$ having a rosette-type morphology; (c) $\mathrm{VOPO}_{4} \cdot 2 \mathrm{H}_{2} \mathrm{O}$ (VPDO) showing an octagonal morphology with both $\{110\}$ - and $\{100\}$-type termination facets; (d) catalyst precursor VOHPO $_{4} \cdot 0.5 \mathrm{H}_{2} \mathrm{O}(\mathrm{VPDOB})$ with a nanoscale rhomboidal morphology.

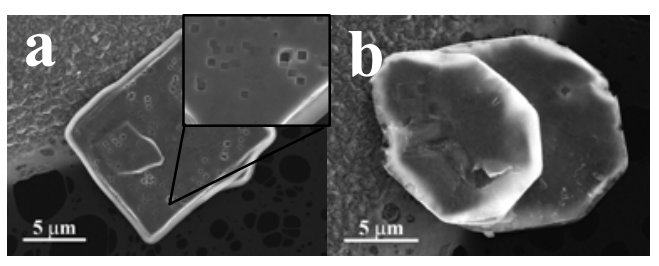

Figure 2. SEM micrographs of (a) cuboidal $\mathrm{VOPO}_{4} \cdot 2 \mathrm{H}_{2} \mathrm{O}$ material (VPD) after exposure to 1-butanol showing etch pits (inset: enlargement of pits having $\{100\}$-type edges) and (b) octagonal $\mathrm{VOPO}_{4} \cdot 2 \mathrm{H}_{2} \mathrm{O}$ materials (VPDO) after treatment with 1-butanol showing few etch pits, but gross $\{100\}$ and $\{110\}$ external facets.

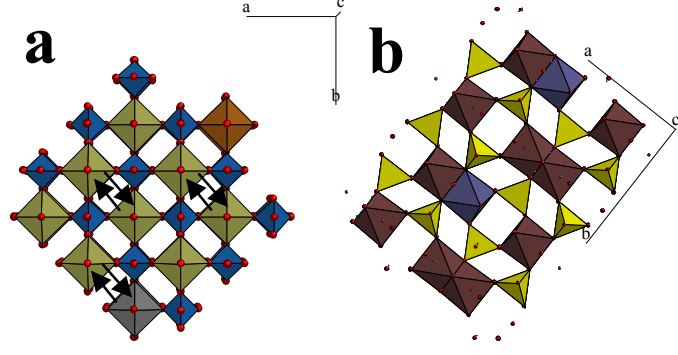

Figure 3. Structural models of (a) the [001] projection of $\mathrm{VOPO}_{4} \cdot 2 \mathrm{H}_{2} \mathrm{O}$ (blue units - $\mathrm{PO}_{4}$ tetrahedra, remainder - $\mathrm{VO}_{6}$ octahedra); (b) [001] projection of $\mathrm{VOHPO}_{4} \cdot 0.5 \mathrm{H}_{2} \mathrm{O}$ (yellow tetrahedra - $\mathrm{PO}_{4}$, remainder - $\mathrm{VO}_{6}$ octahedra). These are oriented in space as they would be (a) before and (b) after the structural transformation. 